\title{
Desinfecção de mudas e do solo com óleo de eucalipto na produção de
}

\section{mandioquinha-salsa}

Heredia Zárate, Néstor Antonio ${ }^{1,4}$; Kátia Regina Freitas Schwan-Estrada2; Maria do Carmo Vieira"; Silvia Cristina Heredia Vieira ${ }^{3}$; Elissandra Pacito Torales ${ }^{1}$; João Dimas Graciano (in memoriam $)^{1}$

${ }^{1}$ Faculdade de Ciências Agrárias, Universidade Federal da Grande Dourados; ${ }^{2}$ Centro de Ciências Agrárias Universidade Estadual de Maringá; ${ }^{3}$ Curso de Farmácia, Universidade Anhanguera;

${ }^{4}$ NestorZarate@ufgd.edu.br

Heredia Zárate, Néstor Antonio; Kátia Regina Freitas Schwan-Estrada; Maria do Carmo Vieira; Silvia Cristina Heredia Vieira; Elissandra Pacito Torales; João Dimas Graciano (2019) Desinfecção de mudas e do solo com óleo de eucalipto na produção de mandioquinha-salsa. Rev. Fac. Agron. Vol 118 (1): 19-23.

\begin{abstract}
Foi estudado o efeito do óleo de eucalipto na desinfecção de mudas e do solo sobre a produção e no controle de doenças durante o ciclo de cultivo da mandioquinha-salsa 'Amarela de Carandaí'. Os tratamentos originaram-se do fatorial 2 (sem-MS e com-MC desinfecção das mudas em solução aquosa com 1\% do óleo, por 35 ”) x 3 (semSSPOE e com-SCPOE pulverização do solo, antes ou depois do plantio, com solução aquosa com $2 \%$ do óleo). Foram realizadas colheitas das plantas aos 224 e 266 dias após o plantio-DAP. As massas frescas de folhas, rebentos e coroas foram semelhantes estatisticamente dentre as MS mas, dentro das MC, os maiores valores corresponderam às plantadas em SCPOE. As maiores produções de raízes comerciais aos 224DAP (5,94 e 6,90 $\left.\mathrm{t} \mathrm{ha}^{-1}\right)$ e aos 266DAP (7,07 e 7,47 $\mathrm{t} \mathrm{ha}^{-1}$ ) foram dos tratamentos onde as MS e MC foram plantadas em SCPOE antes do plantio. Foram observados sintomas de queima das folhas (associação de Alternaria sp. e de Septoria sp.) e de podridões das coroas e dos rebentos (Sclerotium sp.). Concluiu-se que, para se obter maior produção de raízes comerciais da mandioquinha-salsa, usando mudas desinfetadas ou não, deve-se pulverizar óleo de eucalipto no solo antes do plantio, embora sem esperar efeito sobre doenças foliares e podridões de final de ciclo.
\end{abstract}

Palavras-chave: Arracacia xanthorrhiza, controle alternativo de doenças, produtividade.

Heredia Zárate, Néstor Antonio; Kátia Regina Freitas Schwan-Estrada; Maria do Carmo Vieira; Silvia Cristina Heredia Vieira; Elissandra Pacito Torales; João Dimas Graciano (2019) Disinfection of cuttings and of soil with eucalyptus oil on Peruvian carrot yield. Rev. Fac. Agron. Vol 118 (1): 19-23.

The effect of eucalyptus oil as disinfectant of cuttings and of soil on yield and disease control during cultivation cycle of 'Amarela de Carandaí' Peruvian carrot, was studied. Treatments were originated from 2 (without-MS and with MC disinfection of cuttings in aqueous solution with $1 \%$ of oil, for 35 ") $\times 3$ (without-SSPOE and with-SCPOE sprinkling on the soil, before and after planting, with aqueous solution with $2 \%$ of oil) factorial scheme. Harvests were done on 224 and 266 days after planting-DAP. Fresh masses of leaves, shoots and crowns were similar statistically among MS but, among MC, the highest values corresponded to those planted in SCPOE. The highest yields of commercial roots on 224DAP (5.94 and $6.90 \mathrm{t} \mathrm{ha}^{-1}$ ) and 266DAP (7.07 and $7.47 \mathrm{t} \mathrm{ha}^{-1}$ ) were from treatments where MS and MC were planted in SCPOE before planting. Symptoms of burning leaves (association of Alternaria sp and of Septoria sp) and of rot of crows and shoots (Sclerotium sp) were observed. It was concluded that, in order to obtaining a greater yield of commercial roots of Peruvian carrot, using cuttings that were disinfected or not, eucalyptus oil must be sprinkled on soil before planting, although without waiting effects on foliar diseases and rots at the final of the cycle.

Keywords: Arracacia xanthorrhiza, alternative control of disease, productivity.

https://doi.org/10.24215/16699513e002

https://revistas.unlp.edu.ar/revagro

Recibido: 04/01/2016

Aceptado: $10 / 12 / 2018$

Disponible on line: 01/07/2019

ISSN 0041-8676 - ISSN (on line) 1669-9513, Facultad de Ciencias Agrarias y Forestales, UNLP, Argentina 


\section{INTRODUÇÃO}

O cultivo de mandioquinha-salsa (Arracacia xanthorrhiza Bancroft) tem como vantagem a rusticidade; porém, perdas economicamente significativas podem ocorrer quando cuidados básicos de manejo não são tomados, dentre eles, os mais críticos são o cultivo repetido no mesmo terreno, utilização de mudas de má qualidade, cultivo em condições climáticas desfavoráveis para a cultura, preparo do solo/adubação inadequados e irrigação feita sem controle, principalmente com excesso de água. É uma espécie na qual os tratos culturais são efetuados, na maioria das vezes, manualmente, demandando considerável mão-de-obra (Bueno, 2004).

Segundo Vieira et al. (2002), vários autores relatam que um dos fatores que tem limitado a expansão da cultura de mandioquinha-salsa é a falta de material de plantio e, por isso, é recomendado o bom aproveitamento das mudas. A importância de se conhecer bem o tipo, o tamanho e a forma como a muda deve ser plantada está principalmente no fato de o ciclo da cultura ser longo e, portanto, ser necessário estabelecer o mais rápido a população final desejada.

Para o estabelecimento de plantios comerciais de mandioquinha-salsa, o preparo correto das mudas é fundamental para o seu enraizamento e a emergência uniforme das plantas no campo. O método mais comum é o de destacar os rebentos das touceiras, cortar as folhas, deixando 2 a $3 \mathrm{~cm}$ de pecíolo e na base do rebento fazer um corte transversal, horizontal ou em bisel, expondo a região cambial, que apresenta um anel amarelo. Para prevenção de doenças no campo recomenda-se, dentre outros, usarem mudas sadias, evitar o plantio em terrenos onde tenham sido plantadas culturas suscetíveis a patógenos que infectam a mandioquinha-salsa, fazer rotação de culturas, evitarem plantios em períodos quentes e chuvosos, realizar bom preparo do solo e manejo das irrigações e remover plantas doentes juntamente com o solo diretamente em contato com elas (Granate et al., 2007).

Sobre o tratamento das mudas, há poucas informações, embora um dos problemas de cultivo mais frequentes seja o baixo estande final, em relação ao número de mudas plantadas, causado, muitas vezes, pelo ataque de patógenos comuns em plantios comerciais, como Rhizopus sp. e Erwinia sp. (Brune et al., 1996, citados por Vieira et al., 2011). Pode ser feito o tratamento das mudas por imersão em solução de hipoclorito de sódio em água, na proporção de 1:9, durante cinco a dez minutos, para prevenção de doenças e nematóides (Granate et al., 2007).

A procura por novos agentes antimicrobianos, a partir de plantas, é intensa devido à crescente resistência dos micro-organismos patogênicos aos produtos sintéticos. Frente a esse problema, uma estratégia atual da agricultura vem sendo a busca de métodos alternativos para o controle de doenças e pragas, que diminuem os danos ao ambiente e à saúde humana. Trabalhos desenvolvidos com extratos brutos ou óleos essenciais, obtidos a partir de plantas medicinais tem indicado o potencial delas no controle de fitopatógenos (Amaral \& Bara, 2005). Existem diversas teorias sobre a função dos óleos essenciais dos eucaliptos, mas poucos fatos caracterizam seu papel ecológico e fisiológico. Eles já foram considerados como repelentes de insetos que se alimentam de suas folhas, inibidores da germinação e de crescimento de outras plantas, controladores da atividade microbiológica de alguns fungos e bactérias, entre outros (Salgado et al., 2003).

Em função do exposto, o objetivo do trabalho foi estudar o efeito do óleo de eucalipto (Eucalyptus globulus Labill) utilizado na desinfecção de mudas e do solo sobre a produção e no controle de doenças durante o ciclo de cultivo da mandioquinha-salsa 'Amarela de Carandaí'.

\section{METODOLOGIA}

O trabalho experimental foi desenvolvido na Faculdade de Ciências Agrárias da Universidade Federal da Grande Dourados - UFGD, em solo do tipo Latossolo Vermelho distroférrico, textura muito argilosa. com os seguintes atributos químicos: 6,0 de $\mathrm{pH}$ em água; 26,6 $\mathrm{g} \mathrm{dm}^{-3}$ de M.O; 31,0 mg dm${ }^{-3}$ de P; 6,1; 46,6; 18,0; 110,7 e $70,7 \mathrm{mmol}_{\mathrm{c}} \mathrm{dm}^{-3}$ de $\mathrm{K}, \mathrm{Ca}, \mathrm{Mg}, \mathrm{CTC}$ e soma de bases, respectivamente, e $63,0 \%$ de saturação de bases. A área experimental situa-se nas coordenadas de $22^{\circ} 11^{\prime} 44^{\prime \prime} S$ e $54^{\circ} 56^{\prime} 08^{\prime \prime} W$ e altitude de $430 \mathrm{~m}$. O clima da região, segundo a classificação de Köppen Geiger, é do tipo Aw (Peel et al., 2007) com médias anuais para precipitação e temperatura de $1425 \mathrm{~mm}$ e $22^{\circ} \mathrm{C}$, respectivamente.

O trabalho foi iniciado com a desinfecção das mudas em solução aquosa a $1 \%$ de óleo de eucalipto, por 35 ". Os tratamentos originaram-se do fatorial 2 (sem e com desinfecção das mudas) x 3 (sem e com pulverização do solo, antes e depois do plantio). A pulverização do solo foi feita com solução aquosa contendo $2 \%$ de óleo de eucalipto. Para melhorar a aderência foi utilizado o espalhante-adesivo Cittowett $\AA$, na dose de $40 \mathrm{ml}$ para 100 litros de água. Os seis tratamentos foram arranjados no delineamento de blocos casualizados, com quatro repetições. A unidade experimental foi composta por um canteiro com área total de $3,0 \mathrm{~m}^{2}(1,5$ $\mathrm{m}$ de largura $\times 2,0 \mathrm{~m}$ de comprimento) e área útil de 2,0 $\mathrm{m}^{2} \quad(1,0 \mathrm{~m}$ de largura $\times 2,0 \mathrm{~m}$ de comprimento), contendo duas fileiras de dez plantas, espaçadas de $0,60 \mathrm{~m}$ entre elas e $0,20 \mathrm{~m}$ entre plantas, resultando na população de 66.000 plantas ha $^{-1}$.

As mudas para o plantio foram rebentos classificados pela massa nas classes 1 (20,02 g), 2 (15,01 g), 3 $(12,22 \mathrm{~g})$ e $4(11,69 \mathrm{~g})$, sendo cada classe sorteada para fazer parte de uma repetição. No dia anterior ao do plantio, as mudas foram selecionadas e desinfectadas conforme os tratamentos. No dia de plantio, os rebentos foram cortados horizontalmente na parte basal, colocados no fundo dos sulcos de plantio, com os ápices para cima e cobertos com solo (Heredia Zárate et al., 2008) e, imediatamente após, foi feita a pulverização com o óleo de eucalipto, nas parcelas correspondentes.

Não foi feita calagem para correção do solo nem adubação. As irrigações foram feitas utilizando o sistema de aspersão, sendo que na fase inicial, até as plantas apresentarem em torno de $10 \mathrm{~cm}$ de altura, os turnos de rega foram diários e, posteriormente, a cada dois dias. As capinas foram feitas com enxada, entre os 
canteiros, e manualmente, dentro dos canteiros.

Durante o ciclo de cultivo das plantas, avaliaram-se o pegamento das mudas, aos 86 dias após o plantioDAP; a sobrevivência das plantas, aos 224 DAP e os sintomas de doenças na parte aérea das plantas, aos 114, 147 e 183 DAP, avaliando-se, a severidade e a incidência. No solo avaliou-se apenas a incidência, entre 182 e 223 DAP. A caracterização dos patógenos foi realizada nos Laboratórios de Fitopatologia da UFGD e de Microbiologia da Universidade Estadual de Maringá-UEM. A severidade das doenças foi determinada visualmente, utilizando-se escala de 0,00 (sem sintoma de infecção) a 5,00 (planta morta).

Foram realizadas duas colheitas, sendo a primeira aos 224 DAP e a segunda aos 266 DAP, quando as plantas apresentavam como indicativo do ponto de colheita o amarelecimento e secamento de mais de $50 \%$ (Heredia Zárate et al., 2008) e de $70 \%$, respectivamente, das folhas externas das plantas. Nas colheitas foram avaliadas as produções de massas frescas de folhas, rebentos, coroas e raízes comerciais (maiores que 30 g) e não-comerciais (menores que $30 \mathrm{~g}$ ). Os dados foram submetidos à análise de variância e, quando detectou-se significância pelo teste $F$, as médias foram comparadas pelo teste de Tukey a $5 \%$ de probabilidade.

\section{RESULTADOS E DISCUSSÃO}

\section{Produção}

Os estandes de pegamento das mudas e de sobrevivência das plantas e as massas frescas de folhas, rebentos, coroas, raízes comerciais e não comerciais de plantas de mandioquinha-salsa, colhidas aos 224 DAP foram influenciados significativamente pela interação desinfecção das mudas e pulverização do solo com óleo de eucalipto (Tabela 1).

Os maiores estandes de pegamento foram das mudas sem-MS $(95,00 \%)$ ou com-MC $(93,76 \%)$ desinfecção plantadas em solo pulverizado com óleo de eucaliptoSCPOE depois do plantio e os menores foram das MS $(91,26 \%)$ e MC $(76,26 \%)$ plantadas em SCPOE antes do plantio. As menores percentagens de pegamento das $M C$, em relação às $M S$, mostram que houve provável aumento do gasto de fotossintatos de reserva para ativar mecanismos de defesa latentes, existentes na planta, em resposta ao tratamento com agentes abióticos (Schwan-Estrada et al., 2008). Em conseqüência, deve ter diminuído a quantidade de fotossintatos de reserva para uso na emissão do sistema radicular, base para a absorção de água e de nutrientes necessários para a manutenção dos tecidos de brotação, que inicialmente devem sobreviver pelo uso das reservas existentes nas mudas.

Os menores estandes de pegamento das mudas plantadas em solo com pulverização de óleo de eucalipto-SCPOE antes do plantio (Tabela 1), em relação à aquelas em SSPOE e, principalmente, às plantadas em SCPOE após o plantio, que tiveram os maiores estandes, independentes de as mudas serem ou não desinfectadas, permitem levantar a hipótese de ter havido contato do óleo de eucalipto com a área cortada na base da muda (Heredia Zárate et al., 2008) induzindo diferentes graus de prováveis "queimaduras" no córtex, onde se encontram os tecidos parenquimáticos e meristemas responsáveis pela emissão de raízes nas mudas. Os estandes de sobrevivência das plantas foram independentes das formas de desinfecção das mudas e da pulverização do solo com o óleo, mas foram menores do que do pegamento. As falhas no estande quando as mudas de mandioquinha-salsa são plantadas diretamente no campo de cultivo podem ocorrer, segundo Leblanc et al. (2008), devido ao apodrecimento ou por florescimento precoce. O apodrecimento é devido ao não enraizamento e/ou à ação de patógenos.

As produções de massa fresca de folhas, rebentos e coroas foram influenciados pela pulverização do solo apenas quando foram desinfectadas, sendo os menores valores correspondentes às plantadas em SCPOE depois do plantio. Essa resposta mostra relação com a citação de Kuhn (2007), de que as plantas que investem seus recursos para se defenderem na ausência de patógenos arcarão com custos que refletirão na produtividade, uma vez que, as alterações metabólicas que levam à resistência têm um custo adaptativo associado, o qual pode pesar mais do que o benefício.

Tabela 1. Estandes de pegamento e de sobrevivência e massas frescas de folhas, rebentos, coroas e raízes comerciais e não-comerciais de plantas de mandioquinha-salsa originadas de mudas sem e com desinfecção e plantadas em solo sem e com pulverização, antes ou após o plantio, com óleo de eucalipto, na colheita aos 224 dias após o plantio. Médias seguidas pelas mesmas letras minúsculas, nas colunas, dentro de cada forma de desinfecção das mudas, não diferem pelo teste de Tukey, a $5 \%$ de probabilidade. C.V.= Coeficiente de variação.

\begin{tabular}{|c|c|c|c|c|c|c|c|c|}
\hline \multirow[b]{2}{*}{$\begin{array}{l}\text { Desinfecção } \\
\text { mudas }\end{array}$} & \multirow[b]{2}{*}{$\begin{array}{c}\text { Pulverização } \\
\text { solo }\end{array}$} & \multicolumn{2}{|c|}{ Estande (mil ha ${ }^{-1}$ ) } & \multicolumn{5}{|c|}{ Massa fresca $\left(\mathrm{t} \mathrm{ha}^{-1}\right)$} \\
\hline & & Pegamento & Sobrevivência & Folhas & Rebento & Coroa & $\begin{array}{c}\text { Raiz } \\
\text { comercial }\end{array}$ & $\begin{array}{l}\text { Raiz não } \\
\text { comercial }\end{array}$ \\
\hline \multirow{3}{*}{ Sem } & Sem & $61,88 a$ & $51,98 a$ & $3,87 a$ & $2,94 a$ & $3,37 a$ & $4,51 \mathrm{~b}$ & $1,13 b$ \\
\hline & Antes & $60,23 a$ & $47,85 a$ & $3,75 a$ & $3,25 a$ & $3,68 \mathrm{a}$ & $5,94 a$ & $1,45 a$ \\
\hline & Depois & $62,70 \mathrm{a}$ & $45,38 a$ & $4,00 a$ & $2,62 a$ & $3,13 a$ & $4,96 a b$ & $1,20 \mathrm{ab}$ \\
\hline \multirow{3}{*}{ Com } & Sem & $59,40 a b$ & $40,43 a$ & $4,41 a b$ & $3,16 a b$ & $4,04 a$ & $6,66 a$ & $1,45 b$ \\
\hline & Antes & $50,33 \mathrm{~b}$ & $39,60 a$ & $5,20 a$ & $3,78 a$ & $3,60 a b$ & $6,90 a$ & $1,65 a$ \\
\hline & Depois & $61,88 a$ & $45,38 a$ & $3,00 \mathrm{~b}$ & $2,72 \mathrm{~b}$ & $3,16 \mathrm{~b}$ & $4,04 \mathrm{~b}$ & $1,43 \mathrm{~b}$ \\
\hline \multicolumn{2}{|c|}{ C.V. (\%) } & 8,04 & 9,94 & 10,61 & 11,71 & 15,67 & 18,70 & 15,20 \\
\hline
\end{tabular}


As maiores produções de raízes comerciais $(5,94$ e $\left.6,90 \mathrm{t} \mathrm{ha}^{-1}\right)$ e não-comerciais $\left(1,45\right.$ e 1,65 $\left.\mathrm{t} \mathrm{ha}^{-1}\right)$ foram dos tratamentos onde as MS e MC foram plantadas em SCPOE antes do plantio.

Considerando que esses tratamentos foram os que apresentaram os menores estandes de pegamento e de sobrevivência e o tratamento onde as MC apresentaram a maior massa de folhas, então, esses resultados mostram relação com a citação de Larcher (2000) sobre os sistemas vegetais terem mecanismos de auto-regulação, com base na capacidade de adaptação do organismo individual e das populações ou no equilíbrio das relações de interferência, como competição por nutrientes, água e outros.

As massas frescas de folhas, rebentos, coroas, raiz comercial e raiz não-comercial (Tabela 2) das plantas de mandioquinha-salsa, colhidas aos 266 DAP foram influenciadas significativamente pela interação desinfecção das mudas e pulverização do solo com óleo de eucalipto. As maiores massas dos diferentes componentes botânicos foram das plantas MS e plantadas em SSPOE, exceto da raiz comercial $(7,07 \mathrm{t}$ $\left.\mathrm{ha}^{-1}\right)$ que foi das MS plantadas em SCPOE antes do plantio. Nas MC as respostas foram variáveis, mas com maior produção de raízes comerciais $\left(7,47 \mathrm{t} \mathrm{ha}^{-1}\right)$ nas plantadas em SCPOE antes do plantio. Esses resultados confirmam a tendência observada na colheita aos 224 DAP e a citação de Larcher (2000), sobre os sistemas ecológicos terem capacidade de auto-regulação, com base no equilíbrio das relações de interferência. Isso porque, as relações fonte-dreno podem ser alteradas pelas condições de cultivo. As menores produções observadas aos 266 DAP para folhas, rebentos e coroas e as maiores produções de raízes comerciais e não-comerciais, em relação à colheita aos 224 DAP mostram que as plantas da mandioquinha-salsa tinham alcançado a maturidade e o máximo crescimento vegetativo.

As menores massas de rebentos e coroas devem-se, provavelmente, ao fato deles serem órgãos caulinares de transporte e armazenamento e, como tal, serem responsáveis pela conexão do transporte de fotoassimilados desde a parte aérea até as raízes. Conseqüentemente, sua massa é variável em função das forças do dreno, que nessa espécie, é constituído, principalmente, pelas raízes tuberosas (Graciano et al., 2006). Essa hipótese mostra relação com os aumentos de 0,57 e $1,13 \mathrm{t} \mathrm{ha}^{-1}$ de raízes comerciais apresentados pelos tratamentos MC e MS plantadas em SCPOE antes do plantio, em relação às produções obtidas nos mesmos tratamentos, que foram os melhores, na colheita aos 224 DAP.

\section{Doenças}

Foram observados sintomas de queima das folhas, com avaliações aos 114, 147 e 183 DAP e de podridões das coroas e dos rebentos, entre 182 e 223 DAP. Os agentes patogênicos responsáveis pela queima das folhas foram Alternaria sp e Septoria sp, apresentandose associados e sem possibilidade de quantificação unitária. A severidade das infecções foi dependente da desinfecção ou não das mudas e da época de avaliação, em forma isolada (Tabela 3 ). Em relação às podridões, o principal agente fitopatogênico foi Sclerotium sp e a incidência foi influenciada pela interação desinfecção das mudas e pulverização do solo com óleo de eucalipto.

A menor severidade dos fungos foliares (Tabela 3) e a menor incidência de podridões (entre 3,30\%, no tratamento mudas sem desinfecção e solo sem pulverização e $9,90 \%$, no tratamento mudas sem desinfecção e solo com pulverização depois do plantio) foram observadas nas plantas originadas de mudas não tratadas com óleo de eucalipto.

Esses resultados podem ser devidos, segundo SchwanEstrada et al. (2000), à provável produção pelas plantas de fitoalexinas, metabólitos secundários, antimicrobianos, em resposta a estresses físicos, químicos ou biológicos, capazes de impedir ou reduzir a atividade de agentes patogênicos. Essa hipótese é realçada com a maior severidade e maior incidência fitopatogênica nas plantas originadas de mudas desinfectadas com o óleo de eucalipto, nas quais, a provável proteção conferida pelo óleo não foi capaz da indução de resistência (ou indução de proteção, imunidade adquirida ou resistência sistêmica adquirida) que envolve a ativação de mecanismos de defesa latentes, existentes nas plantas em resposta ao tratamento com agentes bióticos ou abióticos (SchwanEstrada et al., 2000).

Os sintomas de queima nas folhas e de podridões das coroas e rebentos das plantas de mandioquinha-salsa foram observados com maior severidade e incidência, respectivamente, nas épocas em que a temperatura e a pluviosidade aumentaram.

Tabela 2. Massas frescas de folhas, rebentos, coroas, raiz comercial e raiz não comercial de plantas de mandioquinhasalsa originadas de mudas sem e com desinfecção e plantadas em solo sem e com desinfecção, antes ou após o plantio, com óleo de eucalipto, aos 266 dias após o plantio. Médias seguidas pelas mesmas letras minúsculas, nas colunas, dentro de cada forma de desinfecção das mudas, não diferem pelo teste de Tukey, a 5\% de probabilidade. C.V. $=$ Coeficiente de variação.

\begin{tabular}{ccccccc}
\hline \multirow{2}{*}{$\begin{array}{c}\text { Desinfecção } \\
\text { mudas }\end{array}$} & $\begin{array}{c}\text { Pulverização } \\
\text { solo }\end{array}$ & Folhas & Rebento & Coroa & $\begin{array}{c}\text { Raiz } \\
\text { Comercial }\end{array}$ & $\begin{array}{c}\text { Raiz não } \\
\text { comercial }\end{array}$ \\
\cline { 3 - 7 } & Sem & $3,17 \mathrm{a}$ & $3,99 \mathrm{a}$ & $3,82 \mathrm{a}$ & $5,64 \mathrm{~b}$ & $1,91 \mathrm{a}$ \\
\multirow{2}{*}{ Sem } & Antes & $2,36 \mathrm{~b}$ & $3,75 \mathrm{ab}$ & $3,16 \mathrm{~b}$ & $7,07 \mathrm{a}$ & $1,38 \mathrm{~b}$ \\
& Depois & $2,00 \mathrm{~b}$ & $3,03 \mathrm{~b}$ & $2,54 \mathrm{c}$ & $4,84 \mathrm{~b}$ & $1,63 \mathrm{ab}$ \\
\hline \multirow{2}{*}{$\mathrm{C}$ Com } & Sem & $2,18 \mathrm{~b}$ & $2,71 \mathrm{~b}$ & $3,21 \mathrm{a}$ & $5,03 \mathrm{~b}$ & $1,28 \mathrm{~b}$ \\
& Antes & $2,93 \mathrm{a}$ & $4,33 \mathrm{a}$ & $3,10 \mathrm{a}$ & $7,47 \mathrm{a}$ & $1,62 \mathrm{ab}$ \\
& Depois & $2,68 \mathrm{ab}$ & $3,67 \mathrm{ab}$ & $2,87 \mathrm{a}$ & $4,90 \mathrm{~b}$ & $1,77 \mathrm{a}$ \\
\hline & C.V. (\%) & 17,30 & 15,18 & 10,14 & 20,07 & 19,43 \\
\hline
\end{tabular}


Tabela 3. Severidade da infecção com doenças foliares de plantas de mandioquinha-salsa originadas de mudas sem e com desinfecção e plantadas em solo sem e com pulverização, antes ou após o plantio, com óleo de eucalipto, em três épocas de avaliação após o plantio. ${ }^{1}$ Notas de 0,00 (planta sem infecção) a 5,00 (planta morta). ${ }^{2}$ Em relação ao plantio. ${ }^{3}$ Dias após o plantio. Médias seguidas pelas mesmas letras minúsculas, nas colunas, não diferem pelo teste de Tukey, a $5 \%$ de probabilidade.

\begin{tabular}{|c|c|c|c|c|c|}
\hline $\begin{array}{c}\text { Desinfecção } \\
\text { das mudas }\end{array}$ & $\begin{array}{c}\text { Nota da } \\
\text { severidade }^{1}\end{array}$ & $\begin{array}{c}\text { Pulverização } \\
\text { do solo }\end{array}$ & $\begin{array}{c}\text { Nota da } \\
\text { severidade }\end{array}$ & $\begin{array}{l}\text { Época de } \\
\text { avaliação }\end{array}$ & $\begin{array}{c}\text { Nota da } \\
\text { severidade }\end{array}$ \\
\hline Sem & $0,43 \mathrm{~b}$ & Sem & $0,48 \mathrm{a}$ & 114 & $0,37 b$ \\
\hline \multirow[t]{2}{*}{ Com } & $0,51 \mathrm{a}$ & Antes & $0,46 \mathrm{a}$ & 147 & $0,21 \mathrm{~b}$ \\
\hline & & Depois & $0,47 \mathrm{a}$ & 183 & $0,83 a$ \\
\hline
\end{tabular}

Em relação à queima nas folhas foram observadas duas épocas críticas. A primeira foi a partir do segundo decêndio de agosto $(\approx 100$ DAP $)$, quando as temperaturas diurnas e noturnas aumentaram e ficaram em torno de $30^{\circ} \mathrm{C}$ e $15^{\circ} \mathrm{C}$, respectivamente e a umidade do ambiente aumentou devido às altas precipitações ocorridas no período, em torno de $100 \mathrm{~mm}$. A segunda época foi no início de outubro $(\approx 180 \mathrm{DAP})$ quando a temperatura e as precipitações iniciaram um novo ciclo de aumento. Quanto às podridões, o início das mortes das plantas começou no terceiro decêndio de outubro, quando houve altas temperaturas, em torno de $35^{\circ} \mathrm{C}$, e quando as plantas estavam na fase de engrossamento das raízes de reserva.

\section{CONCLUSÕES}

Nas condições em que foi conduzido o experimento concluiu-se que, para se obter maior produção de raízes comerciais da mandioquinha-salsa, usando mudas desinfectadas ou não, deve-se pulverizar óleo de eucalipto no solo antes do plantio, embora sem esperar efeito sobre doenças foliares e podridões de final de ciclo.

\section{Agradecimentos}

Ao CNPq, pelas bolsas concedidas; à FUNDECT-MS, pelo apoio financeiro e à UEM, pela oportunidade para efetuar o Pós-doutorado.

\section{REFERÊNCIAS}

Amaral, M.F.Z.J. \& M.T.F. Bara. 2005. Avaliação da atividade antifúngica de extratos de plantas sobre o crescimento de fitopatógenos. Revista Eletrônica de Farmácia 2: 5-8.

Bueno, S.C.S. 2004. Produção de mandioquinha-salsa (Arracacia xanthorrhiza B.) utilizando diferentes tipos de propágulos. Tese. Universidade de São Paulo, Piracicaba, Brasil. 93p.

Graciano, J.D., N.A. Heredia Zárate, M.C. Vieira, Y.B.C. Jardim Rosa, M.A.N. Sediyama \& E.T. Rodrigues. 2006. Efeito da cobertura do solo com cama-de-frango semidecomposta sobre dois clones de mandioquinha-salsa. Acta Scientiarum: Agronomy 28: 365-371.

Granate, M.J., M.A.N. Sediyama \& M. Puiatti. Batatabaroa ou mandioquinha-salsa (Arracacia xanthorrhiza
Banc.). 2007. In: Paula Júnior, T.J. \& M. Venzon. (Coordenadores). 101 culturas: manual de tecnologias agrícolas. EPAMIG, Belo Horizonte. p.137-142.

Heredia Zárate, N.A., M.C. Vieira, J. Rech, A. Quast, B.C.A. Pontim \& R.P. Gassi. 2008. Yield and gross income of arracacha in monocrop and intercropping with the Japanese bunching onion and parsley. Horticultura Brasileira 26: 277-281.

Kuhn, O.J. 2007. Indução de resistência em feijoeiro (Phaseolus vulgaris) por acinbezolar-S-metil e Bacillus cereus: aspectos fisiológicos, bioquímicos e parâmetros de crescimento e produção. Tese. Universidade de São Paulo, Piracicaba, Brasil, 138p.

Larcher, W. 2000. Ecofisiologia vegetal. RiMa Artes e Textos, São Carlos. 531p.

Leblanc, R.E.G., M. Puiatti, M.A.N. Sediyama, F.L. Finger \& G.V. Miranda. 2008. Influência do préenraizamento e de tipos de mudas sobre a população, crescimento e produção da mandioquinha-salsa "Roxa de Viçosa". Revista Ceres 55: 74-82.

Peel, M.C., B.L. Finlayson \& A. McMahont. 2007. A. Updated world map of the Köppen-Geiger climate classification. Hydrology and Earth System Sciences 4: 439-473.

Salgado, A.P.S., M.G. Cardosos, P.E. Souza, J.A. Souza, C.M.P. Abreu \& J.E.B. Pinto. 2003. Avaliação da atividade fungitóxica de óleos essenciais de folhas de Eucalyptus sobre Fusarium oxysporum, Botrytis cinerea e Bipolaris sorokiniana. Ciência e Agrotecnologia 27: 249-254.

Schwan-Estrada, K.R.F., J.R. Stangarlin \& M.E.S. Cruz. 2000. Uso de extratos vegetais no controle de fungos fitopatogênicos. Floresta 30: 129-138.

Schwan-Estrada, K.R.F., C.C.L.F. Suzuki \& A.T. Itako. 2008. Utilização de extratos vegetais no controle de doenças de plantas. In: Poltronieri, L.S. \& A.K. Ishida. N. (Editores.). Métodos alternativos de controle de insetos-praga, doenças e plantas daninhas: Panorama atual e perspectivas na agricultura. EMBRAPA, Belém. p.131-152.

Vieira, M.C., N.A. Heredia Zárate \& H.E. Gomes. 2002. Produção de mandioquinha-salsa em função da desinfecção de mudas e da cobertura do solo com cama de frango semidecomposta. Ciência e Agrotecnologia Edição Especial: 1465-1470.

Vieira, M.C., K.R.F. Schwan-Estrada, N.A. Heredia Zárate, N. Pelisson, C.M.S. Sangalli \& M.F.S. Paula. 2011. Desinfecção das mudas com óleo de eucalipto na produção e controle de doenças da mandioquinhasalsa. Semina: Ciências Agrárias 32: 421-432. 